\title{
Gestão do trabalho docente: o "dramático" uso de si
}

\section{Managing the work of teaching: The "dramatic" use of self}

\author{
Eliana Perez Gonçalves de Moura ${ }^{1}$
}

\begin{abstract}
RESUMO
Aborda os processos coletivos, por meio dos quais os professores produzem-se sujeitos do trabalho, engendrados numa dimensão da experiência laboral que escapa à lógica da organização do trabalho e às práticas de gerenciamento nas escolas. Problematiza os modelos de formação em serviço, concebidos como estratégias de controle e padronização da prática docente. Propõe a gestão do trabalho docente como uma ação inerente à experiência, que supõe escolhas entre uma hierarquização de atos, de objetivos e de valores, assim como, uma tensão "dramática" do uso de si "por si" e "pelos outros".

Palavras-chave: gestão do trabalho; trabalho docente; formação em serviço; subjetividade.
\end{abstract}

\begin{abstract}
This study discusses the collective processes adopted by teachers to produce themselves as subjects of work and engendered at a dimension of work experience that escapes the logic of work organization and school management practices. In-service training models are discussed in that they are conceived as strategies of control and standardization of teaching practices. Teaching should be managed as an action inherent to experience, which depends on choices made from a series of hierarchically ranked acts,
\end{abstract}

1. Doutora em Educação - PUC/RS; Prof ${ }^{a}$. Pesquisadora do Mestrado em inclusão social e Acessibilidade na FEEVALE/RS; elianapgm@feevale.br. 
objective and values, as well as on the dramatic tension between the use of self "for oneself" and "for others".

Keywords: work management; teaching; in-service training; subjectivity.

\section{Introdução}

A profissão docente funda-se em códigos e modelos que prescrevem e instauram as condutas e posturas profissionais, definindo formas peculiares de ser professor em diferentes espaços e épocas. Inicialmente, codificada "por um modo de competência passiva e uma definição de ofício migrada da égide científica", cada vez mais, a prática docente tem sido solicitada a posicionar-se ante a uma nova forma padronizada de ser professor, lançando os docentes à uma outra ordem de codificação como sujeitos do trabalho. Trata-se da instauração de um novo modo de "saber de si no fulcro da prática formativa", protagonizado, particularmente, por meio das práticas (reflexivas) de formação em serviço (AQUINO; MUSSI, 2001, p. 14).

Com efeito, em nossa trajetória de pesquisas ${ }^{2}$ temos observado condutas e práticas docentes referenciadas nos padrões e modelos estabelecidos pela nova lógica da organização do trabalho e nos novos estilos de gerenciamento nas escolas. Esses modelos e códigos, ao mesmo tempo em que definem os modos pelos quais os professores produzem-se sujeitos de sua prática laboral, colocam em movimento a força e o efeito da instituição ${ }^{3}$ Educação, por meio de diversos estilos de gerenciamento do trabalho nas escolas.

2. Projeto de pesquisa, de base qualitativa, articulado em torno das categorias "trabalho e formação docente", "prática e inovação pedagógica" e "organização e gestão do trabalho na escola" desenvolvido com professores de $5^{\mathrm{a}}$ a $8^{\mathrm{a}}$ série do ensino fundamental, das redes de ensino público e privado, da cidade de Novo Hamburgo/RS.

3. Por instituição, entende-se, com Baremblitt (1994, p. 177), o conjunto de decisões lógicas que regulam as atividades humanas, indicando o que é proibido, o que é permitido e o que é indiferente, as quais, segundo seu grau de objetivação e formalização, podem estar expressas em Leis (princípios-fundamentos), normas ou pautas. 


\section{Formação em serviço ou estratégias de padronização do trabalho docente?}

Por formação em serviço entendemos as práticas de formação docente que ocorrem justapostas à experiência do ofício e no próprio local de trabalho, ao contrário, daquelas que ocorrem em um tempo anterior ao ingresso no exercício efetivo da profissão e em âmbitos distintos do locus de trabalho.

Constitui um recurso de formação profissional no interior da prática educativa cujo objetivo é divulgar métodos e técnicas de trabalhar - concebidos como os mais adequados para o alcance de resultados "esperados" - alinhados à lógica de administração do trabalho docente. Trata-se de um modelo "corretivo" da formação inicial e, ao mesmo tempo, regulador da prática educativa que visa alcançar a padronização das condutas cotidianas dos professores, na medida em que opera validando procedimentos, disseminando saberes "úteis" e alterando ou constrangendo comportamentos considerados desajustados ao ofício (FUSARI,1998).

Nessa perspectiva, a formação em serviço produz uma nova racionalização da prática profissional e monopoliza a constituição e circulação dos saberes docentes definindo, no interior da profissão, modos hegemônicos de ser professor.

Deste modo, as práticas de formação em serviço, ainda que ocorrendo no interior das escolas, constituem uma estratégia de intervenção e gerenciamento do trabalho docente similar àquelas que, no âmbito das organizações empresariais, denominam-se treinamento ou capacitação de "recursos humanos". Nas últimas décadas, a formação em serviço passou

[...] a ter presença constante no exercício da profissão, acionada sempre que os mandantes institucionais julgassem necessário dispô-la. Nesse sentido, a formação em serviço operou uma dilatação dos mecanismos de poder sobre a profissão, ao funcionar como campo de validação dos tipos de saber que deveriam circular no exercício mesmo da docência, indicando gradualmente maneiras de se proceder no ofício. Um outro efeito ensejado, talvez, fosse o de anular qualquer proposição de dúvida ou estado de esmorecimento que acompanhasse o professor na rotina de seu posto. Este deveria apresentar-se seguro e convicto daquilo que deveria ser, dizer e fazer em seu cotidiano profissional (AQUINO; MUSSI, 2001, p. 16). 
Desde as primeiras propostas de formação em serviço, formuladas a partir do final da década de 1970 e inspiradas pelas ciências sociais - particularmente, na sua vertente marxista - muitas experiências foram desenvolvidas e revisadas no contexto educacional. Seguindo um contínuo processo de "depuração" os programas recentes de formação docente em serviço, consolidaram-se como propostas que passaram a conceber os professores como profissionais reflexivos, firmando como objetivo, a construção de um novo repertório de experiências de si e apresentando-se como ocasião de "convencer" os professores de sua importância profissional.

Em geral, pleiteiam valorizar os modos de pensar e agir dos professores, convocando-os a saberem-se sujeitos do conhecimento, gestores de sua prática educativa, investigadores de si mesmos, experimentadores autônomos de seu ofício e centro de decisão das transformações no campo da educação.

Com efeito, as práticas atuais de formação em serviço não se ordenam, apenas, por um contingente de conhecimentos externos e alheios aos professores. Circunstanciadas no modelo teórico-reflexivo, os programas de formação em serviço tem-se formulado como uma prática pela qual os professores orquestrariam sua conduta profissional via um procedimento sistemático de reflexão de si, exercitando sua capacidade crítica e produzindo outros saberes por meio dos constantes debates no âmbito da escola.

Desse modo, as práticas de formação docente concomitantes ao exercício da profissão vêm produzindo novas formas de existência na docência, marcadas pela homogeneização das condutas dos professores, produzindo um ambiente que impossibilita aos professores escaparem às formas de dominação e submissão presentes nas relações de trabalho na escola.

\section{Administração escolar, trabalho docente e heranças do taylorismo}

Nas sociedades ocidentais do século XIX e da primeira metade do século $\mathrm{XX}$, as primeiras escolas eram constituídas por um reduzido quadro de pessoal. No nível de ensino primário, por exemplo, havia a escola de classe única, na qual apenas um docente cuidava de tudo e, no nível de ensino secundário público, a escola era constituída por um diretor, um zelador e alguns poucos docentes "generalistas", os quais, além das tarefas pedagógicas, com frequência, também davam conta de outras tarefas vinculadas à vida escolar, como por exemplo: a limpeza das salas (TARDIF; LEVASSEUR, 2004).

Foi somente após a segunda guerra mundial que, aos poucos, esse quadro foi mudando, sobretudo nas cidades, na proporção direta do crescimento do número de alunos e da ampliação do ensino público. Paulatinamente, o trabalho 
efetuado pelo conjunto dos agentes escolares tornou-se mais especializado ${ }^{4} \mathrm{e}$ subdividiu-se em funções e tarefas cada vez mais específicas.

Esse processo implicou a institucionalização de modos específicos de gerenciamento dos sistemas escolares e conduziu à emergência de um modelo "profissional" de administração da educação, o qual incidiu diretamente sobre a divisão do trabalho incrementando o crescimento do trabalho técnico especializado nas escolas. Além disso, inúmeras outras mudanças sociais incitaram e continuam incitando a introdução de novos e cada vez mais sofisticados modelos de gerenciamento dos comportamentos ${ }^{5}$ dos professores dentro das escolas.

Particularmente, no Brasil, desde que a gestão democrática do ensino público passou a ser uma exigência legal, em 1988, os sistemas de ensino viram-se diante do desafio de criar instrumentos e canais de participação mais efetivos na administração das escolas. Na prática, essa exigência constitucional implicou a necessidade de implementar outras formas de administração escolar, nas quais, o modelo de formação em serviço - sobretudo o modelo teórico-reflexivo - passou a ser adotado como um eficaz recurso à gestão democrática nas escolas.

Contudo, faz-se necessário problematizar seriamente essa concepção de gestão, considerando-se que constitui um termo um tanto ambíguo. Cunhado no interior do campo das ciências da administração, em geral, o termo gestão diz respeito à tomada de decisões em organizações empresariais, à direção de ações reunidas em torno de um objetivo econômico comum. Relaciona-se à atividade de impulsionar uma organização a cumprir suas metas, atingir seus objetivos "comerciais".

No campo educacional, diz-se que a gestão da educação deve visar o cumprimento dos princípios da própria educação, assegurando uma educação comprometida com a "sabedoria" de viver junto, respeitando as diferenças, comprometida com a construção de um mundo mais humano e justo para todos os que nele habitam, independentemente de raça, cor, credo ou opção de vida (FERREIRA, 2004, p. 306-307).

Na sua acepção corrente, gestão da educação significa tomar decisões, organizar e dirigir as políticas educacionais que se desenvolvem na escola,

4. Trata-se de uma especialização segundo a lógica taylorista, conforme um determinado posto em que o trabalho profissional já tenha passado por uma análise taylorista.

5. Não é objetivo desta exposição, aprofundar tal análise. Contudo, cabe ressaltar que hoje, os altos administradores têm uma visão abrangente da organização escolar - particularmente da rede privada - graças à introdução das novas tecnologias e de novos sistemas de informação que permitiram uma mudança na forma de controle do trabalho. Hoje, os trabalhadores em educação passaram a ser submetidos, não mais a um controle presencial, mas a um controle "eletrônico", virtual. Trata-se de uma nova trama de controle no trabalho docente que não deixa muito espaço aos professores, para "esconderem-se" em qualquer parte da rede. 
comprometidas com a formação da cidadania, no contexto de globalização da cultura.

Essas tentativas de definição do termo gestão têm como objetivo, buscar "iluminar" uma ação profissional, no campo educacional, "minada" de incertezas e imprecisões, tornando-a consequente com o próprio conceito de educação, a fim de tomar decisões sobre como formar e como garantir a qualidade dos processos educativos.

Contudo, neste debate, uma questão básica precisa ser enfrentada: quem é o agente da tomada de decisões? Quem é o sujeito que toma para si esta responsabilidade? Quem é o agente da gestão do trabalho docente? Essa questão encerra um tema, ainda, obscuro nos debates sobre a gestão do e no campo educacional.

\section{Gestão do trabalho docente: impasses e perspectivas}

O termo gestão, etimologicamente, pressupõe, pelo menos, um ou mais interlocutores com os quais se dialoga pela arte de interrogar e pela atitude de buscar respostas que possam auxiliar no governo da educação. Implica o diálogo como forma superior de encontro das pessoas e solução de conflitos (CURY, 2002, p. 165).

Nesta perspectiva, cabe indagar porque o termo gestão vincula-se à ideia de uma prática profissional especializada, pela qual alguns poucos sujeitos podem e devem definir, prescrever e conduzir as práticas do conjunto de todos os agentes do trabalho educativo?

Ocorre-nos buscar um possível esboço de resposta à essa questão, analisando alguns elementos que evidenciam uma clara transposição das teorias hegemônicas do campo da administração para o campo educacional.

As teorias gerais da administração fundaram-se na esteira da tradição taylorista, cujo problema central assenta-se na pressuposição de uma "natural" indolência humana para o trabalho, impondo aos profissionais da administração a árdua tarefa de identificar as exceções, ou seja, aqueles (poucos) sujeitos que seriam "naturalmente" motivados para o trabalho.

Desse modo, a literatura dessa área desenvolveu-se em torno da seguinte questão: como intervir e controlar o "fator humano no trabalho"? De acordo com essa perspectiva, o investimento subjetivo do homem no trabalho, precisa ser monitorado a fim de construir-se um "saber ser" na dinâmica social que produza sinergias coletivas no trabalho. Trata-se, portanto, de uma dimensão da atividade humana que implica uma "qualquer coisa a mais" que é dada pela(s) pessoa(s) engajada(s) em um serviço a ser realizado em comum. Nesta perspectiva, o 
trabalho situa-se no registro do mecânico, da "execução", do assujeitamento, uma dimensão em que o sujeito do trabalho não pode se expressar a não ser fora do trabalho (SCHWARTZ, 2000).

Contudo, mesmo as mais avançadas teorias administrativas jamais conseguiram inteiramente explicar e "controlar" o funcionamento do "fator humano". Apesar do incessante esforço para o desenvolvimento de técnicas voltadas ao gerenciamento do trabalho humano, ao serem aplicados, tais procedimentos demonstram uma inevitável insuficiência, pois se revelam incapazes de antecipar inteiramente a complexidade de cada situação de trabalho, ainda que, os resultados das atividades laborais sempre sejam alcançados, graças a essa "enigmática alquimia".

Essa questão parece paradoxal porque sob a inspiração das teorias administrativas e dos modelos tayloristas, têm-se a impressão de que nada é mais oposto aos interesses do trabalho do que a subjetividade.

É assim que, visando superar tal paradoxo, propõe-se uma nova forma de abordar o trabalho docente, afirmando-se a existência de um enigmático "sujeito" do trabalho, numa perspectiva que opera um movimento de reconsideração das teorias tayloristas da administração, enfocando-se e valorizando uma entidade sem a qual não há trabalho, no coração mesmo do trabalho.

Essa perspectiva assume que o trabalho docente ocorre em um ambiente que é sempre, mais ou menos imprevisível, mais ou menos "infiel". Nele, todos os tipos de infidelidades se combinam, acumulam-se, reforçam-se umas nas outras porque o ambiente do trabalho docente é sempre, ao mesmo tempo, um ambiente técnico, um ambiente humano, um ambiente cultural (SCHWARTZ, 2000, p. 25).

Desse modo, a infidelidade do trabalho impõe ao docente necessidade de fazer uso de suas próprias capacidades, de seus próprios recursos e de suas próprias escolhas para lograr que seu trabalho se realize. É assim que - gerindo as infidelidades do meio - pode-se propor o termo gestão como um "uso de si" no trabalho, concebendo-o como uma ação que não se restringe a alguns poucos "especialistas", mas que é condição necessária para o professor viver no trabalho educativo.

Aliás, o docente só pode viver seu trabalho na medida em que tenta recentralizar o ambiente (mesmo que no infinitesimal) em torno daquilo que são suas próprias normas, porque viver não se resume somente a executar ordens, submeter-se às regras, às normas. Pelo contrário, ser completamente determinado pelas normas do ambiente do trabalho, não é "viver", porque a vida é sempre tentativa de parcialmente criar-se, talvez, com dificuldade, mas mesmo assim, como centro de um processo e não como produto (SCHWARTZ, 2000).

Desse modo, deve-se reconhecer que o professor sempre fará escolhas em 
seu trabalho, visto que as normas, as prescrições ou as ordens são sempre insuficientes obrigando-o a construir suas próprias leis para preencher o que falta.

Portanto, assim colocada, como verdadeiro problema humano, a gestão advém por toda a parte onde há variabilidade, onde é necessário fazer funcionar sem poder recorrer a procedimentos estereotipados. Toda gestão supõe escolhas, arbitragens, uma hierarquização de atos e de objetivos, portanto, de valores em nome dos quais essas decisões se elaboram. Ora, o trabalho nunca é totalmente - o que quer dizer que em parte ele o é - expectativa do mesmo e repetição (SCHWARTZ, 2000, p. 22).

Isso faz com que não se possa jamais pretender, totalmente, de maneira exaustiva, antecipadamente listar tudo aquilo que compõe o ambiente de trabalho porque as normas antecedentes são sempre insuficientes, porque em todo trabalho, há sempre um "vazio de normas".

Ao propor-se uma nova abordagem, um novo modo de conceber a gestão do trabalho docente, reconhecendo-se a existência de um enigmático "sujeito" do trabalho, pode-se afirmar que não são, apenas, alguns os agentes da tomada de decisões no trabalho docente, mas que todos os professores tomam para si a responsabilidade de fazer escolhas, arbitragens no trabalho. Pode-se, enfim, reconhecer que todos os professores são agentes da gestão do (seu) trabalho docente.

\section{Trabalho docente como uso de si}

"O trabalho dos professores não é uma tarefa simples!" Essa frase resume o alcance filosófico da atividade educativa e expressa a dimensão gestionária, aí implicada a qual somente podemos acessar enfocando as arbitragens, as escolhas que estão presentes nos embates de normas e de valores, impondo aos docentes um constante apelo ao "uso de si" e não apenas à execução, porque é impossível evitar-se a variabilidade no trabalho educacional.

Por isso, qualquer tentativa de encadeamento de procedimentos previamente definidos (aquilo que os modelos de formação em serviço visam implementar), não é suficiente para garantir que o trabalho ocorra tal como foi planejado. $\mathrm{Ou}$ seja, quando os professores trabalham, não há uma simples submissão a procedimentos técnicos, à execução estrita e prescrita de uma tarefa didática, mas há, principalmente, o uso de seus próprios recursos e potencialidades.

Desse modo, o docente - como centro singular de seu trabalho - é incitado a preencher as inevitáveis deficiências das normas, das ordens ou dos conselhos. Queiramos ou não, será seu modo pessoal de responder que dará ao ambiente do 
trabalho uma dimensão justamente ressingularizada. Cada professor tentará, à sua maneira, com sua própria história, seus próprios valores, fazer seu trabalho "com" as lacunas ou deficiências presentes na situação.

Neste sentido, o ambiente do trabalho docente é, sempre, duplamente infiel. Seja porque - por um lado - é impossível uma padronização absoluta; seja porque - por outro - ele próprio é incapaz de predeterminar inteiramente sua atividade. Essas duas infidelidades alimentam-se reciprocamente. Ao gerir a infidelidade crônica do meio, os professores aumentam essa infidelidade pelos toques novos que cada um dá ao seu trabalho. Por isso diz-se que sempre haverá uma espécie de destino a viver, porque sempre será necessário fazer escolhas que, de um lado, são feitas em função de valores pessoais e, de outro, representam um risco de transgressão às normas instituídas.

Ao trabalhar o docente sempre correrá riscos porque, para suprir os "vazios de normas", a deficiência de ordens, de conselhos, de experiências registradas em regras ou procedimentos, ele antecipa soluções possíveis que são passíveis de falhas, de criar dificuldades novas, de desagradar. Quando os professores escolhem uma ou outra opção, uma ou outra hipótese escolhem a si mesmos e, ao mesmo tempo, escolhem o risco de assumir as consequências de suas escolhas. Consequentemente, toda atividade docente tem qualquer coisa "dramática" porque sempre remete a um movimento que é individual, mas também coletivo.

Com efeito, o professor jamais trabalha sozinho, porque seu trabalho está imerso em um universo social no qual, pelas escolhas, pelas arbitragens, engaja-se em um mundo humano atravessado de valores. Por tudo isso, trabalhar é sempre um elemento de escolha ante uma resposta que é sempre, em parte, também coletiva (SCHWARTZ, 2000).

Deste ponto de vista, no âmbito do trabalho em educação, trabalhar será sempre uma fonte de desempenho ou de não desempenho, de eficácia ou de ineficácia tomando-se como referência a presença e o "olhar" dos outros. No trabalho docente, os "outros" podem ser os colegas próximos, aqueles que escolhemos, mas também são aqueles que avaliam nosso trabalho, aqueles que esperam um trabalho de qualidade, aqueles que nos julgam ou que nos pagam.

Enfim, o trabalho docente está atravessado pelos “outros” que está presente na intimidade das escolhas, as quais definem a forma de relação que desejamos estabelecer com os outros, ou o mundo no qual gostaríamos de viver.

Assim, o modo com o qual cada um negocia esse encontro com os outros, efetivamente, remete aos dramas mais radicais da tarefa docente. Escolhendo as coisas menores, o docente escolhe modos de vida, seus modos de relação com outros, seus projetos, heranças, enfim, aquilo que torna sua vida singular. 


\section{A dramática do uso de si no trabalho docente}

Em toda organização do trabalho, há uma realidade coletiva e ao mesmo tempo, individual porque as pessoas não são anônimas; são pessoas singularizadas por sua história pessoal. Por isso, não é possível prescrever a maneira pela qual uma organização do trabalho poderá funcionar. Pelo contrário, o que define uma organização do trabalho é o modo particular como as pessoas constroem essas "realidades" coletivas aos olhos dos outros e em relação às prescrições e padronizações do trabalho. Isso remete à singularidade dos vínculos que são estabelecidos, de escolhas que são feitas, e que tornam tais "realidades" relativamente pertinentes, no entanto, frágeis.

Com efeito, as prescrições da organização do trabalho remetem a um verdadeiro trabalho de construção de si que pode falhar, que é difícil e caro para os docentes e que, definitivamente, não é prescrito. Nessas construções, os docentes não são intercambiáveis, senão estar-se-ia reportando a alguma coisa que pode existir e ser formada antes mesmo que a atividade coletiva se desenvolva. A forma como um professor se produz lhe é própria porque sempre haverá um re-trabalho a fazer cujo resultado não será jamais previsto antecipadamente. Portanto, é necessário pensar a presença do outro, no íntimo das escolhas de si por si mesmo, mas inversamente, a maneira como um professor responde aos outros é inelutavelmente pessoal. Efetivamente, não é possível esquivar-se dessa responsabilidade pessoal na construção coletiva da organização do trabalho, por isso, é preciso pensar essas duas dimensões ao mesmo tempo (SCHWARTZ, 2000).

Essa maneira de pensar a relação entre o individual e o coletivo do e no trabalho docente, torna complexa a noção de motivação que é muito ambígua e, de maneira geral, é vista como o processo de cada um. Com efeito, da forma como tem sido usado no campo da administração, o conceito de motivação parece oferecer a chave de tudo.

Neste sentido, é comum encontrarmos coordenadores que exclamam aos seus pares: "sejam motivados". Contudo, esse tipo de afirmação é vazia e inútil porque encerra a pressuposição de que motivação é alguma coisa que está "dentro" de cada professor, que depende dele/a porque é uma característica psicológica.

Esse tipo de pressuposição ignora que na motivação sempre há um modo de relação estabelecido entre o docente e o meio, porque "estar motivado" não depende unicamente da pessoa, mas, também, do meio onde se trabalha, ou onde se foi colocado para trabalhar. Assim, a questão da motivação refere-se também a atividade, na medida em que essa coloca questões à pessoa, incitando-a 
a fazer uso de si por si, mas também, confrontando-a no uso de si pelos outros (SCHWARTZ, 2000).

O uso de si pelos outros, comporta um drama e expressa o fato de que em todo universo de trabalho reinam normas de todos os tipos: científicas, técnicas, organizacionais, hierárquicas, mas, principalmente, as normas gestionárias que remetem a relações de igualdade/desigualdade; dominação/subordinação; competição/colaboração, amizade/rivalidade, o que significa dizer que cada pessoa tenta viver num meio onde as pressões são muito fortes, onde não se faz o que se quer. Desse modo, o destino a viver-se no trabalho é viver "com" essa pressão. Mas, paradoxalmente, essa pressão é também uma sorte, pois é a possibilidade do sujeito "desanonimar" seu trabalho, tentando fazer valer suas próprias normas de vida, suas próprias referências. Essa tentativa é também um risco, pois os fracassos são possíveis.

Esse problema do trabalho é o que se chama de "dramática" na duração do trabalho (SCHWARTZ, 2000). Mas drama não quer dizer forçosamente tragédia. Drama quer dizer que alguma coisa, ainda que minúscula, sempre acontece no trabalho porque o sujeito arbitra no mais íntimo da atividade. No entanto, não se trata aqui de um "sujeito" delimitado, definido, mas de uma entidade enigmática que resiste às tentativas de objetivá-lo.

\section{Problematizações finais}

Ao problematizarmos os modelos de formação em serviço, concebendo-os como estratégias de controle e padronização da prática docente, não pretendemos desqualificar essas modalidades formativas, mas chamar atenção para seus efeitos como ações concretas que promovem "novas figurações de subjetividade para os professores no tempo presente" (AQUINO e MUSSI, 2001).

Neste sentido, afirmamos nossa compreensão sobre a gestão do trabalho docente como uma ação inerente à experiência de si, que supõe escolhas entre uma hierarquização de atos, de objetivos e de valores, assim como, implica uma tensão "dramática" do uso de si "por si" e "pelos outros" abrindo novas possibilidades de experiência aos professores.

Entendemos que a vivência dessas "novas figurações de subjetividade" é constante e incessantemente re-trabalhada pelos docentes, no interior das relações institucionais, produzindo uma forma peculiar de ser e saber de si no trabalho, que escapa dos objetivos definidos nos programas de formação em serviço.

Por essa razão, propõe-se a abordagem dos processos coletivos que engendram modos de ser professor, elementos que, até hoje, ainda não foram 
vislumbrados no horizonte do campo educacional. Isto implica considerar uma dimensão da experiência laboral docente que escapa não apenas à lógica da organização do trabalho e às práticas de administração nas escolas, mas também, às pautas dos atuais programas de formação em serviço.

Cabe ressaltar que, apesar do seu incontestável avanço na produção do conhecimento científico, entendemos que o campo da educação, precisa acolher essa abordagem sobre o trabalho humano que desloca a noção de gestão, situando-a no "registro da experiência de si em situação". Reconhecendo a presença da dimensão gestionária situada na interface das relações institucionais que se estabelecem entre o professor e seu trabalho, essa nova abordagem promete ventos de renovação aos debates educacionais, pois pode contribuir para fazer avançar algumas enigmáticas questões sobre o trabalho docente, libertando a noção de gestão do rol de atribuições específicas de uma prática profissional especializada.

\section{REFERÊNCIAS}

AQUINO, J. G.; MUSSI, M. C. As vicissitudes da formação docente em serviço: a proposta reflexiva em debate. Educação e Pesquisa, São Paulo, v. 27, n. 2, p. 211-227, jul./dez. 2001. Disponível em: <www.scielo.br>. Acesso em: 17 /1/2007.

BAREMBLITT, G. Compêndio de Análise Institucional e Outras Correntes - teoria e pratica. 2. ed. Rio de Janeiro: Rosa dos Tempos, 1994.

CURY, C. R. J. Direito à educação: direito à igualdade, direito à diferença. Cadernos de Pesquisa, São Paulo, n. 116, 2002. Disponível em: <www.scielo.br>. Acesso em: 12/12/2006.

FERREIRA, N. S. C. Repensando e Ressignificando a Gestão Democrática da Educação na "Cultura Globalizada". Educação e Sociedade, Campinas, v. 25, n. 89, p. 1227-1249, set./dez. 2004. Disponível em: <www.cedes.unicamp.br>. Acesso em: 12/1/2007.

FUSARI, J. C. Formação contínua de educadores: um estudo de representações de coordenadores pedagógicos da Secretaria Municipal de Educação de São Paulo (Smesp). Tese (Doutorado) - Faculdade de Educação, Universidade de São Paulo, São Paulo, 1998.

SCHWARTZ, Y. Travail et gestion: niveaux, critéres, instances. Revue Performances Humaines et Technicque, Paris, n. hors-série, p. 13-45. octares, 2000. 
TARDIF, M.; LEVASSEUR, L. Divisão do Trabalho e Trabalho Técnico nas Escolas de Sociedades Ocidentais. Educação e Sociedade, Campinas, v. 25, n. 89, p. 1275-1297, set./dez. 2004. Disponível em: <www.cedes.unicamp.br>. Acesso em: 5/2/2007. 